Original Research Paper

\title{
Effect of Reflective Training Program on Nurse Interns' Critical Thinking Disposition and Communication Competency
}

\author{
Aisha El Sayed-El Araby Abdelwahid and Nora Mahdy Attia \\ Ph.D., Lecturers of Nursing Administration, Faculty of Nursing, Zagazig University, Egypt
}

Article history

Received: 02-10-2019

Revised: 30-12-2019

Accepted: 11-01-2020

Corresponding Author: Aisha El Sayed-El Araby Abdelwahid

Ph.D., Lecturers of Nursing Administration, Faculty of Nursing, Zagazig University, Egypt

Email: na2435705@yahoo.com

\begin{abstract}
Rapid changes in nursing practice emphasis on nurses' autonomy in the delivery of health care services and give them more responsibility in determining the outcome of their nursing interventions. These skills are the most essential nursing tools in healthcare delivery. So the present study aimed to determine the effect of reflective training program on nurse interns' critical thinking disposition and communication competency. This study was conducted at Zagazig University hospitals, Sharkia Governorate, Egypt. For this research a quasi-experimental design was utilized. Simple random sample of 80 nurse interns who receive their training at the above mentioned setting. Data were collected using three tools; reflective practice questionnaire, critical thinking disposition scale and interpersonal communication competency scale. Results illustrated that there was a significant betterment in nurse interns' reflective practice score after application of the program $(\mathrm{p}<0.01)$. Also, there was statistically significant enhancement in critical thinking disposition score, where P- value $<0.01$. Additionally, there was a statistically significant betterment in total score of communication competence after the program application $(\mathrm{p}<0.01)$. Conclusion: Critical reflection had significant correlation with betterments of both critical thinking disposition and communication competence among nurse interns. Consequently it was recommended that faculty should encourage nursing educators to use reflection as a teaching method to develop students' critical thinking disposition and communication competence.
\end{abstract}

Keywords: Reflective Practice, Critical Thinking Disposition, Communication Competency, Nurse Interns

\section{Introduction}

The internship program begins after successful termination of the four years in the undergraduate nursing program where nursing students must spend 12 months of internship period in certain hospital that can provide proper training that meets the aim of the internship program. This period of theoretical, practical and managerial experience will help each nurse intern to acquire extra competencies and experiences to perform as an independent professional nurse and as a first line nurse manager through applying the essential skills of nursing administration in diverse clinical sittings (Ismail et al., 2015).

During this time, nurse interns will also be prepared to fully understand their prospective responsibilities as professionals and comprehend the boundaries that define ethical and safe practice. Internship period provides nurse interns with the opportunity to work closely with experienced nurses in the clinical setting (Nash et al., 2009). Additionally, a well-planned internship program will help nurse interns to build their clinical confidence and foster their clinical skills while developing professional work qualities and attitudes (Haleem et al., 2011).

Nurses provide nursing care for different patients with diverse symptoms. Therefore the abilities to detect the changes of patients' status and apply proper nursing interventions are highly required to nurses. Nurses with good critical thinking skills can think independently and carefully assess the importance of information over the 
nursing process (Heejeong Kim et al., 2015). An essential component in professional nursing practice is nurses' ability to reflect on their work (Ulric et al., 2010). Reflection influences nursing practice and education around the world. Recently, reflection has gained increased recognition as a crucial part of nursing profession and as an educational strategy to acquire knowledge and learn through practice (Vaz and Prado, 2014). There has been a great interest in reflective practice in nursing field (Edwards, 2014). Reflective practice can bridge the gap between nursing theory and practice, develop and articulate nursing knowledge (Green et al., 2014). It is also known as thinking carefully and deeply, especially about solutions and opinions (Al-Momani and Momania 2013). In education, reflection is defined as "active, careful and persistent consideration of any form of knowledge (Dolphin, 2013). It is considered as an important learning strategy that helps professionals to be aware of their underlying knowledge base (Nielsen et al., 2007). Also, it has been described as involving thinking about and critically analyzing our experiences and actions with the goal of improving our professional practice (Vaz and Prado, 2014).

There are two main forms of reflection: Reflectionon-action and reflection-in-action; Reflection-on-action involves carefully re-running in your mind events that have happened in the past. The purpose is to estimate your strong points and to develop active and different ways of acting in the future. While reflection-in-action is the hallmark of the experienced professionals. It means assessing your own behavior and that of others while in a certain situation (Oluwatoyin, 2015).

Reflective practice is highly valued and strongly recommended in nursing education and practice (Smith et al., 2018). It also contributes to learning; it helps the learner to flatten and criticize the underlying understandings that have been developed around the repetitive experiences of a specialized practice and can develop new sense of the situations which the practice has developed it (Zhang et al., 2011). Reflective practice has many advantages for nurses; it enhances self-esteem, integrates theory with practice, allows nurses to view clinical situations from different perspectives, improves decision making, encourages critical thinking and helps in development of autonomy (Oluwatoyin, 2015; Birks et al., 2016). On the other hand, it could empower nurses as it enables them to render effective nursing care, enhances self-awareness, make them more competent and improve the quality of holistic nursing care, as well as improving critical thinking disposition and communication competency (Hatlevik, 2012).

Healthcare environment characterized by rapidly changing development and never-ending knowledge so critical thinking disposition is an important skill for nurses as it helps them to adapt to these changes, it also, helps them in solving clinical problems and making right judgment (Higgs and Jones, 2015). Critical thinking has two dimensions; a quest for thinking (disposition) and a series of operational cognitive skills. Critical thinking disposition is defined as regular internal motivation to connect problems and make decisions through the use of critical thinking (Bell and Loon, 2015).

There are seven domains of critical thinking disposition include objectivity, prudence, systematicity, intellectual eagerness/curiosity, intellectual fairness, healthy skepticism and critical thinking self-confidence (Shin et al., 2015). Objectivity is a tendency of removing personal biases while prudence is the habitual seeing to what extent the issue is complex. In addition, systematicity is the tendency of striving to connect problems in a regular way. On the other hand, intellectual eagerness/curiosity is the liability to know things (Biber et al., 2013). Intellectual fairness is the tendency of thinking with the opinions of others while healthy skepticism is always searching for the best potential understanding of any given situation. Lastly, CT self-confidence is the susceptibility to trust reflective thinking in problem solving and decision making (Shin et al., 2015).

Communication is defined as the creation of shared meaning. Communication competences, both oral and written, are fundamental in nursing because of the nature of nurse's job (Xu, 2008). Interpersonal communication competence can be defined as the ability to make effective relation with others which is suitable to the needs of each one and to the situation. It is also considered as a process that achieves the objectives of both communication parties; it assumes a basic knowledge of communication, verbal and non-verbal awareness in interactions, clarity and objectivity, as well as promoting self-knowledge (Mantha, 2010). It has five domains; self-disclosure, environmental control, assertiveness, interaction management and immediacy (Puggina and Silva, 2014). Self-disclosure presents a person's ability to demonstrate their feelings and ideas through communication while environmental control demonstrates person's ability in being suited to the environment to achieve their goals. On the other hand, assertiveness involves the proactive ability to protect their rights without denying others' rights, demonstrating security, decision and persistence in situations (Muralidharan et al., 2010). Additionally, interaction management involves the issue of providing feedback in a bidirectional manner, both in terms of demonstrating understanding to self and in relation to what others feel through non-verbal communication. Finally, immediacy indicates that available people can demonstrate to others that they are easily accessible for interpersonal communication (Puggina and Silva, 2014). 


\section{Significance}

When nurse interns enter into the practice environment; they soon face a gap between what they have learned in the classroom and what they see in the real world, as they become more aware that their skills level don't match their expectation of roles and responsibilities of the registered nurse, also frequent contact with patients and families and collaboration among health care team members require good communication competence. On the other hand, the challenges in health care institutions require them to improve their critical thinking, decision making and communication competence. Although it is difficult to promote strategies to improve critical thinking, some researchers suggested that reflection is effective for developing and promoting critical thinking and communication competency as well as it will help nurse interns to be more prepared for both the workforce and life (Zhang et al., 2017). Therefore, it is essential to provide reflective training program to nurse interns with hope that it could improve their critical thinking disposition and communication competence.

Aim

Determine the effect of reflective training program on nurse interns' critical thinking disposition and communication competency.

\section{Hypotheses}

1. Nurse interns' reflective practice score will be increased after program application

2. Nurse interns' critical thinking disposition will be improved after program application

3. Nurse interns' communication competency will be improved after program application

4. There will be a correlation among reflective practice, critical thinking disposition and communication competency of nurse interns after program application

\section{Methodology}

Design

A quasi-experimental design was utilized to accomplish the aim of this study.

\section{Setting}

This study was carried out in different inpatient units of Zagazig University Hospitals where the nurse interns receive their training which included intensive care, newborn, pediatric, obstetric and gynecological and different medical surgical units.

\section{Subjects}

Simple random sample of nurse interns who succeeded in the academic year 2017-2018 and receive their training at Zagazig University Hospitals (2018-2019).

\section{Sample Size}

It was calculated by using a simplified formula provided by Yamane $(1967)\left(\mathrm{n}=\mathrm{N} / 1+\mathrm{N}(\mathrm{e})^{2}\right)$, at confidence interval $95 \%$, margin of errors $5.0 \%$, a total population size of 465 nurse interns; accordingly, the required sample size was 80 nurse interns. They were selected randomly by putting all nurse interns' names in container and start to pick up until collecting the required number.

\section{Instruments}

Three tools were used to collect data for this study.

\section{Tool I: Reflective Practice Questionnaire}

It consists of two parts as follows: The first part: Personal characteristics of nurse interns; this part was used to collect data about gender, age, marital status and working beside internship year. The second part: reflective practice questionnaire: was developed by Priddis and Rogers (2017) to assess nurse interns' knowledge regarding reflection, it consists of 40 items grouped under 10 domains with four items for each domain; reflective-in-action, reflective-on-action, reflective with other, self-appraisal, desire for betterment, Confidence - general, Confidence communication, uncertainty, stress interacting with clients and job satisfaction. The responses were measured on 5-point Likert scale ranged from 1 (strongly disagree) to 5 (strongly agree). Cronbach's alpha was used to assess its internal consistency; it was 0.80 .

\section{Tool II: Critical Thinking Disposition Scale}

It was developed by Kwong et al. (2006) to measure critical thinking disposition of nurse interns. It consists of 35 items grouped under eight domains; intellectual integrity (6items), creativity (4items), challenge (6items), open-mindedness (3items, prudence (4items), objectivity (4items), 'truth seeking (3 items) and inquisitiveness (5items). The responses were measured on 5-point Likert scale ranged from 1 (strongly disagree) to 5 (strongly agree). Cronbach's alpha was 0.89 .

\section{Tool III: Interpersonal Communication Competence Scale}

It was developed by Puggina and Silva (2014) to assesses dimensions of interpersonal communication competence It consists of 17 items grouped under five categories; environmental control (4items), Self- 
disclosure (4items), assertiveness (4items), Interaction management (2items) and immediacy (3items). The responses were measured on 5-point Likert scale ranged from 1 (strongly disagree) to 5 (strongly agree). Cronbach's alpha in this study was 0.71, which illustrated an acceptable degree of internal reliability.

\section{Field Work}

\section{Preparatory Phase}

Started in August to September, 2018 with reviewing the literature of national and international resources related to the topics of the present study. The questionnaires were given to the nurse interns to identify their knowledge regarding reflective practice, critical thinking disposition and interpersonal communication competency. Based on the results of the pre-test, the learning needs of nurse interns' were identified. Therefore, the training program objectives were stated and the content was designed.

\section{Application Phase}

Started in mid-October, 2018 to mid- January, 2019. The training program designed for this study has been carried out through 22 sessions (10 theory and 12 practical sessions). The program was 11 weeks in length and the program sessions was carried out two days per week. The program consisted of two main parts; the theoretical part; covered all relevant knowledge about the program, concept of reflective practice, usefulness, effects of reflective practice, disadvantages, barrier to good reflection and supervisor's role in reflective practice. As well as, steps of reflection was introduced. Part two; is the practical part. Following this, the nurse interns wrote reflections on the basis of case studies developed for learning, therefore they were provided feedback.

\section{Evaluation Phase}

Concerned with estimating the effect of the training program on nurse interns' critical thinking disposition and communication competency using the same tools before application of program.

\section{Pilot Study}

It was conducted before the pretest to make sure of clarity, applicability and understanding of the tools. Additionally, estimating time required for filling the questionnaire. It was carried out on 8 (10\% of the study sample) nurse interns. They were selected randomly and excluded from the main study sample and the result of pilot sample was excluded from the main study results. The necessary modifications were done.

\section{Ethical Consideration}

Content of study was approved by Ethics Committee and dean of the Faculty of Nursing, Zagazig University. Verbal and written explanation of the aim and nature of the study have been explained to nurse interns who participated in the study. The researchers informed the participants that their participation is absolutely voluntary; they could withdraw at any stage of the program without giving any rational. Researchers explained to participants that they aren't forced to write their names with emphasis on confidentiality of the information as it would be used for the research purpose only.

\section{Statistical Analysis}

Data were analyzed by using the Statistical Package for Social Science (SPSS) program, version 21. Data were presented using descriptive statistics in the form of frequencies and percentages for qualitative variables; means and standard deviations for quantitative variables. Paired t- test was used to compare means of two independent groups. For all the tests used, statistical significance was considered at $\mathrm{p}$-value $<0.05$.

\section{Results}

Table 1 shows that $75 \%$ of studied nurse interns were less than 24 years old with mean age 23.48 years. Additionally, the highest percentage of them were females, married and didn't work beside the internship year $(65 \%, 81.25 \%$ and $86.2 \%$ respectively).

Table 2 illustrates that, all domains and total mean score of reflective practice among nurse interns were significantly improved directly after the program application $(\mathrm{P}<0.01)$.

Table 3 clarifies that, all domains and the total mean score of critical thinking disposition among nurse interns significantly improved directly after the program application $(\mathrm{P}<0.01)$.

Table 4 identifies that, all domains and the total mean score of communication competency among nurse interns significantly improved directly after the program application $(\mathrm{P}<0.01)$.

Table 5 reveals that, there was highly statistically significant correlation between reflective practice and communication competency before program application $(\mathrm{r}=0.687$ and $\mathrm{P}<0.05)$. On the other hand, there was highly statistically significant correlation between reflection practice, critical thinking disposition and communication competency after program application $(\mathrm{r}$ $=0.085$ and $\mathrm{P}<0.05)$.

Table 6 demonstrates that, there was no statistically significant relation between nurse interns' reflective practice, critical thinking disposition and communication competency and their personal characteristics before and after program application $(\mathrm{P}<0.01)$. 
Table 1: Personal characteristics of nurse interns $(n=80)$

\begin{tabular}{lll}
\hline Personal characteristics & No & $\%$ \\
\hline Age in year: & & 70 \\
$<24$ & 20 & 75.00 \\
$\geq 24$ & $23.48 \pm 0.729$ & 25.00 \\
Mean \pm SD & & 18.75 \\
Gender: & 15 & 81.25 \\
Male & 65 & 28.80 \\
Female & 23 & 71.20 \\
Marital status: & 57 & 13.80 \\
Single & & 86.20 \\
Married & 11 & 69 \\
Working during the internship year: & 69 & \\
Yes & & \\
No &
\end{tabular}

Table 2: Reflective practice scores throughout the program phases as reported by nurse interns $(\mathrm{n}=80)$

\begin{tabular}{lllll}
\hline Reflective practice domains & $\begin{array}{l}\text { Before Program } \\
\text { application Mean } \pm \text { SD }\end{array}$ & $\begin{array}{l}\text { After Program } \\
\text { application Mean } \pm \text { SD }\end{array}$ & Pairedt-test & P value \\
\hline Reflective-in-action & $10.18 \pm 2.78$ & $15.65 \pm 2.77$ & $12.17^{* *}$ & 0.000 \\
Reflective-on-action & $9.77 \pm 2.35$ & $17.56 \pm 2.84$ & $14.14^{* *}$ & 0.000 \\
Reflective with other & $6.96 \pm 2.62$ & $18.3 \pm 2.55$ & $13.59^{* *}$ & 0.000 \\
Self-appraisal & $7.22 \pm 1.74$ & $22.60 \pm 2.75$ & $3.55^{* *}$ & 0.000 \\
Desire for betterment & $13.50 \pm 2.95$ & $15.50 \pm 3.15$ & $3.96^{* *}$ & 0.000 \\
Confidence-general & $10.55 \pm 2.23$ & $16.17 \pm 2.61$ & $14.91^{* *}$ & 0.000 \\
Confidence-communication & $5.77 \pm 2.77$ & $19.58 \pm 2.77$ & $13.22^{* *}$ & 0.000 \\
Uncertainty & $15.45 \pm 2.81$ & $9.04 \pm 2.45$ & $15.87^{* *}$ & 0.000 \\
Stress interacting with clients & $16.04 \pm 2.98$ & $9.33 \pm 2.75$ & $15.40^{* *}$ & 0.000 \\
Job satisfaction & $9.74 \pm 2.33$ & $14.98 \pm 2.42$ & $12.85^{* *}$ & 0.000 \\
Total score & $117.13 \pm 14.60$ & $159.66 \pm 17.30$ & $19.83^{* *}$ & 0.000 \\
\hline Paired & & &
\end{tabular}

Paired t-test: Compare means scores pre-program and immediate post.

** Highly statistically significant at $\mathrm{P}<0.01$

Table 3: Critical thinking disposition scores throughout the program phases as reported by nurse interns $(\mathrm{n}=80)$

\begin{tabular}{lllrl}
\hline $\begin{array}{l}\text { Critical thinking } \\
\text { disposition domains }\end{array}$ & $\begin{array}{l}\text { Before program } \\
\text { application Mean } \pm \text { SD }\end{array}$ & $\begin{array}{l}\text { After program } \\
\text { application Mean } \pm \text { SD }\end{array}$ & Paired t-test & P value \\
\hline Intellectual integrity & $14.31 \pm 4.04$ & $23.64 \pm 3.33$ & $-14.71^{* *}$ & 0.000 \\
Creativity & $9.85 \pm 2.80$ & $14.89 \pm 4.33$ & $-8.92^{* *}$ & 0.000 \\
Challenge & $16.40 \pm 4.21$ & $21.85 \pm 3.83$ & $-8.12^{* *}$ & 0.000 \\
Open mindedness & $7.09 \pm 2.31$ & $15.96 \pm 2.49$ & $-11.11^{* *}$ & 0.000 \\
Prudence & $9.56 \pm 2.27$ & $20.14 \pm 2.88$ & $-13.28^{* *}$ & 0.000 \\
Objectivity & $10.37 \pm 2.34$ & $16.30 \pm 3.00$ & $-5.19^{* *}$ & 0.000 \\
Truth seeking & $8.04 \pm 2.38$ & $19.06 \pm 2.07$ & $-12.41^{* *}$ & 0.000 \\
Inquisitiveness & $14.32 \pm 3.01$ & $17.54 \pm 3.92$ & $-4.60^{* *}$ & 0.000 \\
Total score & $90.39 \pm 14.62$ & $150.03 \pm 14.73$ & $-16.86^{* *}$ & 0.000 \\
\hline Paired t- & & & &
\end{tabular}

Paired t-test: Compare mean scores pre-program and immediate post.

** Highly statistically significant at $\mathrm{P}<0.01$

Table 4: Communication competency scores throughout the program phases as reported by nurse interns $(n=80)$

\begin{tabular}{lllrl}
\hline $\begin{array}{l}\text { Communication } \\
\text { competency categories }\end{array}$ & $\begin{array}{l}\text { Before Program } \\
\text { application Mean } \pm \text { SD }\end{array}$ & $\begin{array}{l}\text { After Program } \\
\text { application Mean } \pm \text { SD }\end{array}$ & Paired t-test & P value \\
\hline Environmental control & $9.75 \pm 2.24$ & $14.91 \pm 2.08$ & $-12.04 * *$ & 0.000 \\
Self-disclosure & $9.84 \pm 2.41$ & $13.65 \pm 2.24$ & $-9.90 * *$ & 0.000 \\
Assertiveness & $6.41 \pm 1.90$ & $15.38 \pm 2.18$ & $-14.62 * *$ & 0.000 \\
Interaction management & $5.12 \pm 1.39$ & $6.70 \pm 1.21$ & $-7.21^{* *}$ & 0.000 \\
Immediacy & $7.31 \pm 1.82$ & $9.64 \pm 1.92$ & $-7.45^{* *}$ & 0.000 \\
Total score & $38.54 \pm 6.01$ & $60.30 \pm 7.38$ & $-14.58^{* *}$ & 0.000 \\
\hline Pair
\end{tabular}

Paired t-test: Compare mean scores pre-program and immediate post.

** Highly statistically significant at $\mathrm{P}<0.01$ 
Table 5: Correlation between total scores of reflective practice, critical thinking disposition and communication competency of nurse interns through the program phase $n=80$

\begin{tabular}{|c|c|c|c|c|c|c|c|c|}
\hline \multirow[b]{3}{*}{ Variables } & \multicolumn{4}{|c|}{ Before the program $(n=81)$} & \multicolumn{4}{|c|}{ After the program $(\mathrm{n}=81)$} \\
\hline & \multicolumn{2}{|c|}{$\begin{array}{l}\text { Critical thinking } \\
\text { disposition }\end{array}$} & \multicolumn{2}{|c|}{$\begin{array}{l}\text { Communication } \\
\text { competency }\end{array}$} & \multicolumn{2}{|c|}{$\begin{array}{l}\text { Critical thinking } \\
\text { disposition }\end{array}$} & \multicolumn{2}{|c|}{$\begin{array}{l}\text { Communication } \\
\text { competency }\end{array}$} \\
\hline & $\mathrm{R}$ & $\mathrm{P}$ & $\mathrm{R}$ & $\mathrm{P}$ & $\mathrm{R}$ & $\mathrm{P}$ & $\mathrm{R}$ & $\mathrm{P}$ \\
\hline Reflective practice & 0.085 & 0.448 & $0.678^{* * *}$ & 0.000 & $0.687^{* *}$. & 0.000 & $0.370^{* *}$ & 0.001 \\
\hline
\end{tabular}

Table 6: Relation between personal characteristics of the nurse interns and reflective practice, critical thinking disposition and communication competency $(\mathrm{n}=80)$.

\begin{tabular}{|c|c|c|c|c|c|c|}
\hline \multirow[b]{2}{*}{ Variables } & \multicolumn{3}{|c|}{ Before the program application } & \multicolumn{3}{|c|}{ After the program application } \\
\hline & $\begin{array}{l}\text { Reflection } \\
\text { Mean } \pm \text { SD }\end{array}$ & $\begin{array}{l}\text { Critical thinking } \\
\text { disposition } \\
\text { Mean } \pm \text { SD }\end{array}$ & $\begin{array}{l}\text { Communication } \\
\text { competency } \\
\text { Mean } \pm \text { SD }\end{array}$ & $\begin{array}{l}\text { Reflection } \\
\text { Mean } \pm \text { SD }\end{array}$ & $\begin{array}{l}\text { Critical thinking } \\
\text { disposition } \\
\text { Mean } \pm \text { SD }\end{array}$ & $\begin{array}{l}\text { Communication } \\
\text { competency } \\
\text { Mean } \pm \text { SD }\end{array}$ \\
\hline \multicolumn{7}{|l|}{ Age in years } \\
\hline$<24$ years & $76.22 \pm 6.36$ & $56.38 \pm 5.15$ & $81.38 \pm 13.54$ & $75.74 \pm 7.99$ & $58.65 \pm 5.51$ & $74.62 \pm 17.72$ \\
\hline$\geq 24$ years & $73.13 \pm 6.10$ & $54.23 \pm 5.60$ & $87.67 \pm 12.33$ & $76.90 \pm 5.99$ & $58.83 \pm 5.61$ & $75.00 \pm 14.80$ \\
\hline Independent t-test---P-value & $-0.01-0.99$ & $-0.63-0.52$ & $1.3-0.17$ & $0.47-0.63$ & $0.64-0.49$ & $0.73-0.46$ \\
\hline \multicolumn{7}{|l|}{ Gender: } \\
\hline Male & $83.00 \pm 0.00$ & $52.00 \pm 0.00$ & $87.00 \pm 0.00$ & $76.00 \pm 0.00$ & $61.00 \pm 0.00$ & $90.00 \pm 0.00$ \\
\hline Female & $74.71 \pm 6.28$ & $57.65 \pm 5.36$ & $83.70 \pm 13.78$ & $77.19 \pm 8.32$ & $58.80 \pm 5.58$ & $74.32 \pm 16.64$ \\
\hline Independent t-test---P-value & $2.03-0.19$ & $-0.084-0.37$ & $0.80-0.55$ & $-0.61-0.644$ & $0.32-0.80$ & $0.39-0.75$ \\
\hline \multicolumn{7}{|l|}{ Marital status: } \\
\hline Single & $76.35 \pm 6.93$ & $57.13 \pm 5.52$ & $82.70 \pm 13.46$ & $78.39 \pm 9.30$ & $58.57 \pm 6.17$ & $72.96 \pm 17.68$ \\
\hline Married & $74.19 \pm 5.99$ & $57.75 \pm 5.35$ & $84.16 \pm 13.89$ & $76.68 \pm 7.85$ & $58.93 \pm 5.34$ & $75.14 \pm 16.31$ \\
\hline Independent t-test---P-value & $0.48-0.63$ & $-0.74-0.46$ & $-1.2-0.22$ & $0.46-0.64$ & $-0.61-0.56$ & $-0.55-0.59$ \\
\hline Yes & $77.82 \pm 7.65$ & $59.73 \pm 4.17$ & $80.00 \pm 13.05$ & $79.00 \pm 6.32$ & $60.18 \pm 7.15$ & $71.45 \pm 14.18$ \\
\hline No & $74.33 \pm 5.99$ & $57.23 \pm 5.48$ & $84.33 \pm 13.80$ & $76.88 \pm 8.54$ & $58.61 \pm 5.28$ & $75.00 \pm 17.03$ \\
\hline Independent t-test---P-value & $1.06-0.83$ & $0.90-0.39$ & $-0.29-0.78$ & $0.008-0.94$ & $0.95-0.34$ & $-0.31-0.97$ \\
\hline
\end{tabular}

\section{Discussion}

Reflection is increasingly recognized in nursing field due to its contribution to the learning process and expansion of the body of nursing knowledge. Reflective training program provides nurse interns with opportunities to connect what they have learned in the classroom with current practice and helping them to become active participants. It enhances the learning experience as it enables nurse interns to make connections to the information being taught and motivates them to learn in better way. Additionally, it allows nurse interns to feel confident, attempt new skills and think critically (Nuno and Tiago, 2016). Reflective training during the internship period will improve nurse interns' critical thinking disposition and communication competency. It also helps them to promote their readiness for clinical practices to meet the increasing demands of healthcare environment. Therefore, the aim of this study was to assess the effect of reflective training program on nurse interns' critical thinking disposition and communication competency at Zagazig university hospitals.

Concerning score of nurse interns regarding reflective practice throughout the program phase; there were highly statistically significant betterments in all domains and the total score of reflective practice among nurse interns immediately after the program application. This result supports the first research hypothesis which stated that nurse interns' reflective practice score will be increased after program application.

The previous results may be due to the engagement of nurse interns to the program, effective delivery of the new material that helped them to participate effectively in the activity and the use of their natural story-telling tendencies through personal reflection was helpful for them to understand the concept and application of reflection process. Also, the encouragement by the researchers through role-plays and simulated scenarios enabled nurse intern to organize his or her thoughts quickly. This result is in the same line with Walker et al. (2013); who conducted a study entitled the use of critical reflection process to create an effective learning community in the workplace at Australia and found that there were betterments of the reflection scores after program application.

Similar results reported by Chong (2009) who examined the perception of nurse interns towards reflective practice in their clinical practice at University of Malaya and found that the total mean score of nursing students regarding perceptions on reflective practice increased directly after program application. 
Concerning score of nurse interns regarding critical thinking disposition throughout the program phases, there were highly statistically significant betterments in all domains and the total score of critical thinking disposition among nurse interns immediately after program application. This result proves the second research hypothesis which stated that nurse interns' critical thinking dispositions will be improved after program application.

This betterment could be assigned to one or more rationales, which include the comprehensive content of the educational training program, the written handout of the program which serves as ongoing reference, nurse interns' interest and keenness to learn new things, consideration of the patterns of adult learning, encouragement of questions, interactive talk with the utilization of multimedia and repetition of the knowledge. As well as the satisfaction of nurse interns with the content of the program and their motivation to apply the process of reflection that enhances critical thinking disposition and the desire of nurse interns to gain knowledge to be ready for any critique for his or her own self.

This result confirms the finding of previous study done by Kim et al. (2018) conducted a study on 44 novice nurses working in an advanced general hospital in Korea and found that critical-thinking disposition of novice nurses improved directly after program application. Also, Zhang et al. (2017) studied the effects of reflective training for nursing students on their critical thinking disposition in Medical University in China and found that there was highly statistically differences in all domains and the total mean score of critical thinking disposition among nursing students before and directly after the program application.

In the same line, a study carried out by Dorn (2014) at Florida State University and found that there was statistically significant difference in total mean score of critical thinking disposition after program application.

Regarding score of communication competency throughout the program phases, the current study illustrated that there were highly statistically significant betterments in all domains and total score of communication competency among nurse interns immediately after the program application. This result justifies the third research hypothesis which declared that nurse interns' communication competency will be improved after program application.

The above mentioned results may be due to some possible reasons; reflective training program was helpful for nurse interns to understand the concept of reflective practice and its practical application when communicating with others and they had gained the necessary skills for initiating and maintaining interpersonal relationships.

This result in agreement with that of Farrington and Townsend (2014) who studied nurse- patient communication and critical reflection and found that the total mean scores of the participants regarding communication competency increased immediately after training program application. Also, Kim et al. (2018), who found that critical reflection training program didn't improve novice nurses' communication competency.

With regard to correlations among total score of reflective practice, critical thinking disposition and communication competence as reported by nurse interns throughout the program phases. The results of the current study showed that there was highly statistically significant correlation between reflective practice and communication competency before program application. While there was highly statistically significant correlation among reflective practice, critical thinking disposition and communication competency after program application. These results confirm the fourth hypotheses which declared that there will be a correlation among reflective practice, critical thinking disposition and communication competency of nurse interns.

The previous results may be attributed to reflective practice is an essential component in nursing practice and it has an effect on communication competence and critical thinking; to be a critical thinker, one needs to be self- reflected; and conversely, to be a self-reflected, one needs to be a critical thinker. On the other hand critical thinking is strongly linked with good communication. This result is compatible with Kim et al. (2018) which found statistically significant correlation between total score of reflective practice, critical thinking disposition and communication competency after program application.

With reference to the relationship between different study variables and studied nurse interns' personal characteristics; this research findings indicated no significant relation between nurse interns' reflective practice, critical thinking disposition and communication competency with their personal characteristics before and after program application.

This result could be related to relatively small sample size of nurse interns $(N=80)$ which may adversely affect the discovery of possible relationships among nurse interns' personal characteristics and different study variables. Also the similarity of personal characteristics among studied nurse interns.

These findings are in agreement with a study carried out by Ahmed and Elmolla (2012) who conducted a study in Helwan University, Egypt and reported that there were no statistically significant relations were found between students' critical thinking scores and students' age. As well, Eng and Pai (2013) conducted a study in Taiwan and mentioned that there were no statistical significant differences in the relationship between age and critical thinking disposition. While these results are inconsistent with Hunter et al. (2014) who conducted a study to investigate critical thinking skills among undergraduate nursing students in Australia 
to obtain a profile and determine demographic predictors of critical thinking, reported that nursing students associated experience predicted higher scores for the critical thinking subscales.

\section{Conclusion}

Reflective training program was effective in improving nurse interns' critical thinking disposition and communication competence.

\section{Recommendations}

Based on the findings of the study, the following recommendations are suggested:

- Educational programs should adopt teaching methods that enhance reflection

- Conducting reflective training program for nursing students to explore, think and solve problems actively

- Training program for novice nurse about reflective practice in the orientation period to help them adapt to the working circumstances and reflect on their work

- Faculty should provide training for nurse educators about reflective practice and its importance

\section{Further Research}

- Further research to explore the impact of reflective practice on nurse interns' professional practice, organizational change and patient outcomes.

- Further studies to develop more tools to test the effectiveness of reflection as teaching method.

\section{Authors Contributions}

All authors equally contributed in this work.

\section{Ethics}

This article is original and contains unpublished material. The corresponding author confirms that all of the other authors have read and approved the manuscript and no ethical issues involved.

\section{References}

Ahmed, G.M. and M.A. Elmolla, 2012. Improving critical thinking nursing students: Application of problem based learning scenarios. J. Am. Sci., 8: 1180-1187.

Al-Momani, S. and W. Momania 2013. Facilitating nursing students' compliance with standard precautions through their own reflection. Asian J. Nurs. Educ. Res., 3: 248-253.
Bell, R. and M. Loon, 2015. The impact of critical thinking disposition on learning using business simulations. Int. J. Manage. Educ., 13: 119-127. DOI: 10.1016/j.ijme.2015.01.002

Biber, A.C., A. Tuna and L. Incikabi, 2013. An investigation of critical thinking dispositions of mathematics teacher candidates. Educ. Res., 4: 109-117.

Birks, M., P. Hartin, C. Woods, E. Emmanuel and M. Hitchins, 2016. Students' perceptions of the use of portfolios in nursing and midwifery education. J. Nurse Educ. Pract., 18: 46-51. DOI: 10.1016/j.nepr.2016.03.003

Chong, M.C., 2009. Is reflective practice a useful task for student nurses? Asian Nurs. Res., 3: 111-117. DOI: 10.1016/S1976-1317(09)60022-0

Dolphin, S., 2013. How nursing students can be empowered by reflective practice. Mental Health Pract., 16: 20-23. DOI: $10.7748 / \mathrm{mhp} 2013.06 .16 .9 .20 . \mathrm{e} 867$

Dorn, R.L., 2014. How reflection prompts impact critical thinking skills. PhD Thesis, College of Education. Florida State University.

Edwards, S., 2014. Finding a place for story: Looking beyond reflective practice. Int. Pract. Dev. J., 4: 1-14.

Eng, C.J. and H.C. Pai, 2013. The relationships among critical thinking disposition, caring behavior and learning styles in student nurses. Open J. Nurs., 3: 249-256. DOI: 10.4236/ojn.2013.32034

Farrington, N. and K. Townsend, 2014. Enhancing nurse-patient communication: A critical reflection. British J. Nurse, 24: 771-775. DOI: $10.12968 /$ bjon.2014.23.14.771

Green, J., A. Wyllie and D. Jackson, 2014. Electronic portfolios in nursing education: A review of the literature. Nurse Educ. Pract., 14: 4-8. DOI: 10.1016/j.nepr.2013.08.011

Haleem, D.M., W. Manetti, K. Evanina and R. Gallagher, 2011. A senior internship facilitating the transition to nursing practice. J. Nurse Educ., 36: 208-213. DOI: 10.1097/NNE.0b013e3182297cfc

Hatlevik, I., 2012. The theory-practice relationship: Reflective skills and theoretical knowledge as key factors in bridging the gap between theory and practice in initial nursing education. J. Adv. Nurs., 68: 868-877.

DOI: $10.1111 / \mathrm{j} .1365-2648.2011 .05789 . x$

Heejeong Kim, H., E.K. Lee and S. Park, 2015. Critical thinking disposition, self-efficacy and stress of Korean nursing students. Indian J. Sci. Technol., 18: 1-5. DOI: $10.17485 / \mathrm{ijst} / 2015 / \mathrm{v} 8 \mathrm{i} 18 / 76710$

Higgs, J. and M. Jones, 2015. Clinical Reasoning in the Health Professions. 2nd Edn., ButterworthHeinemann, Oxford. 
Hunter, S., V. Pitt, N. Croce and J. Rochet, 2014. Critical thinking skills of undergraduate nursing students: Description and demographic predictors. Nurse Educ. Today, 34: 809-824.

DOI: 10.1016/j.nedt.2013.08.005

Ismail, M., K. Saber, M. Hegazy, N. Al-amari and S. Salah, 2015. Nursing internship program manual. University of Dammam, College of Nursing.

Kim, Y.H., J. Min, S.H. Kim and S. Shin, 2018. Effects of a work-based critical reflection program for novice nurses. BMC. Medical Educ.

DOI: 10.1186/s12909-018-1135-0

Kwon, I.S., G.E. Lee, G.D. Kim, Y.H. Kim and K.M. Park et al., 2006. Development of a critical thinking disposition scale for nursing students. J. Korean Academic Nurs., 36: 950-8.

DOI: $10.4040 /$ jkan.2006.36.6.950

Mantha, S.S., 2010. Handbook on communication skills. Center for Good Governance, Andhra Pradesh (India).

Muralidharan, A., J. Madsen and W.E. Craighead, 2010. Interpersonal competence across domains: Relevance to personality pathology. J. Personality Disorders, 25: 16-27.

DOI: $10.1521 /$ pedi.2011.25.1.16

Nash, R., P. Lemcke and S. Sacre, 2009. Enhancing transition: an enhanced model of clinical placement for final year nursing students. J. Nurse Educ. Today, 29: 48-56. DOI: 10.1016/j.nedt.2008.06.004

Nielsen, A., S. Stragnell and P. Jester, 2007. Guide for reflection using the clinical judgment model. J. Nurs. Educ., 46: 513-525. DOI: 10.3928/01484834-20071101-06

Nuno, M. and M. Tiago, 2016. Reflective practice among nursing students in clinical teaching. J. Nurs. Ref., 121-131. DOI: 10.12707/RIV16030

Oluwatoyin, F.E., 2015. Reflective practice: Implication for nurses. J. Nursi. Health Sci., 4: 28-33.

Priddis, L. and S. Rogers, 2017. Development of the reflective practice questionnaire: preliminary findings. J. Reflective Pract., 19: 1-16. DOI: 10.1080/14623943.2017.1379384

Puggina, A.C. and M.J. Silva, 2014. Interpersonal communication competence scale: Brazilian translation, validation and cultural adaptation. J. ACTA Paul. Enferm, 27: 108-114.

DOI: $10.1590 / 1982-0194201400020$
Shin, H., C.G. Park and H. Kim, 2015. Validation of Yoon's critical thinking disposition instrument. Asian Nurs. Res., 9: 342-348. DOI: 10.1016/j.anr.2015.10.004

Smith, R.A., S. Andrews, C. Oliver and J.C. Evans, 2018. Putting reflective practice into action: A case study. J. Nurs. Educ. Pract., 8: 36-47.

DOI: 10.5430/jnep.v8n10p36

Ulric, B., C.H. Ashlockch, C. Krozek, L.M. Africa and S. Early et al., 2010. Improving retention, confidence and competence of new graduate nurses: Results from a 10-years longitudinal database. Nurs. Econom. J., 28: 363-75.

Vaz, D. and C. Prado, 2014. Pedagogical reflective practice of nursing undergraduates: The portfolio as an instrument. Nurse Educ. Pract., 48: 1103-1110. DOI: $10.1590 / \mathrm{S} 0080-623420140000700019$

Walker, R., M. Cooke, A. Henderson and D.K. Creedy, 2013. Using a critical reflection process to create an effective learning community in the workplace. Nurse Educ. Today, 33: 504-511. DOI: 10.1016/j.nedt.2012.03.001

$\mathrm{Xu}, \quad \mathrm{Y}$., 2008. Communicative competence of international nurses and patient safety and quality of care. Home Health Care Manage. Pract., 20: 430-432. DOI: $10.1177 / 1084822308316162$

Yamane, T., 1967. Statistics: An Introductory Analysis. 2nd Edn., Harper and Row, New York, pp: 919.

Zhang, C., H. Fan, J. Xia and H. Guo, 2017. The effects of reflective training on the disposition of critical thinking for nursing students in China: A controlled trial. Asian Nurs. Res., 11: 194-200.

DOI: 10.1016/j.anr.2017.07.002

Zhang, L., L. Chen, W. Lin, C. Pan and F. Zhang et al., 2011. Effects of reflection diary in cultivating critical thinking ability of nursing students in operation room. Chinese J. Nurs., 28: 3-21. 